\title{
Assessing the influence of Lake Victoria flux on the Inner Murchison Bay water quality
}

\author{
M. Akurut ${ }^{1,2}$, P. Willems ${ }^{1} \&$ C. B. Niwagaba ${ }^{2}$ \\ ${ }^{1}$ Department of Civil Engineering, KU Leuven, Belgium \\ ${ }^{2}$ Department of Civil and Environmental Engineering, \\ Makerere University Kampala, Uganda
}

\begin{abstract}
Lake Victoria in Eastern Africa is affected by a complex mixture of processes including increased pollution, water level fluctuations, hydrology of upstream catchments and wetland management, flora and fauna populations, etc. This study attempts to analyse effects of water level changes in Lake Victoria on the quality of water in the Inner Murchison Bay (IMB), located on the Northern part of the lake. The complex shoreline structure of bays and gulfs around Lake Victoria hinders accurate determination of the pollutant balance. Consequently, temporal variations in the pollutant concentrations in the Bay are used to monitor its water quality. Delft3D-Flow was applied to study the Bay hydrodynamics and quantify effects of dilution and mixing. This model was coupled with the Delwaq module to investigate the water quality processes related to Oxygen, Organic and Nitrogen nutrient components. Analysis of the measured concentrations over the period 2001-2011 shows that these concentration loadings generally follow an exponential distribution over time. The temporal variations are partly controlled by the lake levels through varying the water flow patterns affecting the residence time of pollutants rather than due to dilution tendencies. Lake levels accounted for only about $90 \%$ of flow in the IMB whose mean residence time was about 60 days. The Delwaq model could reasonably predict water quality variations towards the Outer Bay for $\mathrm{NH}_{4}{ }^{+}$, DO and BOD as lake mixing occurs towards this Outer Bay. The high continuity errors in the Inner Bay may be attributed to high swamp inflows which were neglected in the hydrodynamic simulations. Keywords: Lake Victoria, water levels, water quality, Delft3D.
\end{abstract}




\section{Introduction}

Lake Victoria, Africa's largest fresh water lake covers a surface area of about $68,800 \mathrm{~km}^{2}$ shared across three East African countries; Uganda (45\%), Kenya (6\%), and Tanzania (49\%). The lake has a complex shoreline structure comprising of gulfs and bays that receive municipal and industrial wastes from adjacent urban centres. This research attempts to study influence of the main lake water level variations on the quality of water in the shores. Murchison Bay, located in the Northern part of Lake Victoria in Uganda is the abstraction point for potable water supply in Kampala city and also the recipient for surface runoff, sewage effluent, industrial and municipal wastes from the city. Over the years, Murchison Bay has been threatened by several anthropogenic and natural influences e.g. wetland degradation, over fishing, increased pollution from Kampala, water hyacinth infestation, water level decline (Kaggwa et al. [1]; Haande et al. [2]). The water treatment costs by the National Water \& Sewerage Corporation (NWSC) are said to have trebled in the last decade owing to the fluctuating water levels and deteriorating water quality in the Bay which has threatened the capacity to increase water production for the ever rising population (Kayima et al. [3]; Banadda et al. [4]). Consequently, an alternative water treatment plant has been proposed in the Katosi bight of Lake Victoria about $24 \mathrm{~km}$ further eastward of the Murchison Bay to ensure a more reliable sustainable supply of drinking water in the greater Kampala area. Such transitions however, have to be limited in the future to ensure sustainable economic development. It is therefore important to study the influence of the lake level changes on the shores so as to understand effects of the anthropogenic activities and climatic conditions on the quality of water in the Murchison Bay.

Due to the vast size of the Lake Victoria basin, it has generally been agreed that the average lake rainfall almost balances the annual evapotranspiration such that rainfall variations are believed to significantly influence water levels in the lake. This notion has been applied by several authors to study the water balance of the lake often translated as changes in the lake levels or outflow regimes (Piper et al. [5]; Yin and Nicholson [6]; Tate et al. [7]). Awange et al. [8] explained that $80 \%$ of the Lake Victoria refill was predominantly rainfall compared to the $20 \%$ from basin discharge. Most variations in the water balance of Lake Victoria are attributed to the different calculation periods and methods used in estimation of the different balance components i.e. evapotranspiration, inflows, outflows and precipitation (Yin and Nicholson [6] and Kite [9, 10]).

Swenson and Wahr [11] applied satellite remote sensing data in 2003-2008 to monitor the water balance of Lake Victoria in comparison to other water bodies in the vicinity and showed that climate forcing explained half of the lake level trends while the outflow patterns were responsible for the other half. They also showed that baseflows could be significant in the water budget of the lake especially since evapotranspiration data was directly obtained from the satellite measurements. Kizza et al. [12] improved the spatial rainfall input using grided monthly rainfall with a spatial resolution of $2 \mathrm{~km}$ for both ground based and satellite data for the period 1960-2004 providing a plausible lake balance model 
for this study. This water balance model was used to check satellite decoded lake height variations at the lake midpoint in relation to calculated and measured levels; the water level variations were used to study Lake Victoria fluxes on the Inner Murchison Bay water quality.

\section{Materials and methods}

\subsection{Murchison Bay}

Murchison Bay is located in the south of Kampala City between latitudes $\left(00^{\circ}\right.$ $\left.10^{\prime} 00^{\prime \prime} \mathrm{N}-00^{\circ} 30^{\prime} 00^{\prime \prime} \mathrm{N}\right)$ and longitudes $\left(32^{\circ} 35^{\prime} 00^{\prime \prime} \mathrm{E}-32^{\circ} 50^{\prime} 00^{\prime \prime} \mathrm{E}\right)$ at average elevation of 1134 m.a.s.l. It covers a total area of about $62 \mathrm{~km}^{2}$ and can further be split into the Inner and Outer Bay; as their characteristics differ tremendously. Inner Murchison Bay (IMB) has an area of about $18.4 \mathrm{~km}^{2}$ and an average depth of $3.2 \mathrm{~m}$. The IMB has an average catchment area of $282 \mathrm{~km}^{2}$ comprising of both wetlands and urban areas of the city with the biggest drainage inlet being the Nakivubo channel which passes through Kampala City. In the past, a large portion of the Nakivubo channel has been modified to a concrete walled structure limiting pollutant purification through the ever dwindling wetlands surrounding the IMB (Kansiime and Nalubega [13]; Sekabira et al. [14]). Figure 1(a) shows locations of Kampala and Entebbe Cities around Lake Victoria shoreline. Kampala City is a hub of industrial and commercial activities; it is characterised by a very high population growth rate with current population estimated at about 2 million inhabitants. Central Kampala area is the largest industrial area with an existing sewer network contributing about $33 \%$ $\left(2,700 \mathrm{~m}^{3} / \mathrm{d}\right)$ of industrial discharge. Luzira/Port Bell is the second largest developed project area; It is mostly un-sewered with major industries (Uganda Breweries and Ngege Fish) contributing about $40 \%$ of partially treated discharge

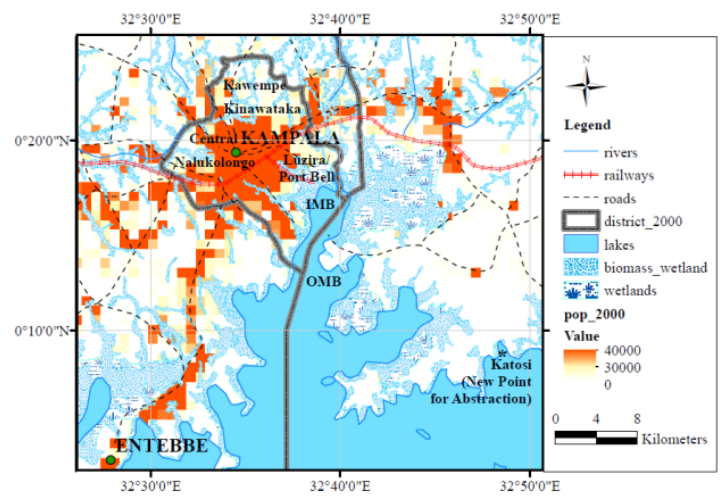

(a)

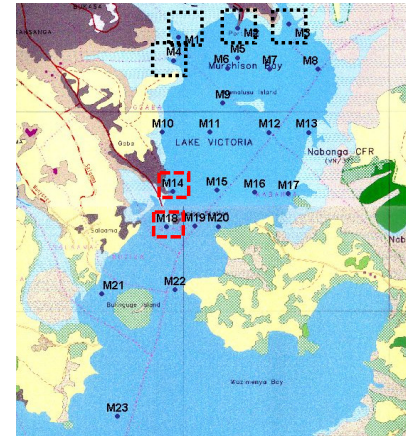

(b)

Figure 1: $\quad$ Location of Kampala City along the lake shore (a) and monitoring points within the Murchison Bay (b). 
from this area. Kinawataka area is the third largest area but its discharge is estimated as the second highest at $1,700 \mathrm{~m}^{3} / \mathrm{d}$ (Fichtner \& M\&E Associates [15]).

\subsection{Data}

In Uganda, Lake Victoria levels are observed at two stations: Jinja and Entebbe. Murchison Bay lies between these two locations. The average elevation at Entebbe (1134 m.a.s.1) is about $0.545 \mathrm{~m}$ higher than Jinja. Satellite lake height variations at the lake midpoint were obtained online from USDA [16]; these measurements were already corrected for water levels measurements at Jinja. The satellite water level variations were checked against measured levels at Entebbe, obtained from Ministry of Water and Environment, Uganda, for consistency. Since, Murchison Bay and Entebbe lie at similar elevations, the satellite levels were adjusted by a correction term of $(+0.545)$ to obtain lake level variations for use in the Murchison Bay hydrodynamic model.

The spatial water quality measurements within the Murchison Bay were obtained from NWSC, Uganda, for the period 2001-2011. Monthly in-situ measurements for Temperature (T) and Dissolved Oxygen (DO) were taken at the different monitoring points within the Bay as shown in Figure 1(b). Samples were also taken at these locations and analysed for various water quality variables in the NWSC Laboratory to monitor the water quality of the Bay. These irregular monthly measurements were sparsely populated and mainly available at periods when the Lake Victoria Environment Management Project (LVEMP) was active. The highest pollution points are located at the Northern part of the IMB and around heavily industrialised and industrial areas namely: M1 (Nakivubo Channel outlet), M2 (Luzira/Port Bell discharge), M3 (Kinawataka stream), and M4 (Kansanga stream). The water abstraction points are located towards the Outer Murchison Bay at M14 and M18 about $4.5 \mathrm{~km}$ downstream of the sewage discharge point located near M1.

Various monitoring programs have been carried out in the IMB but no substantial water quality models have been developed to study the variation of water quality with time in the bay yet, its morphology and activities qualify it to be an ecosystem within the lake's ecosystem. Studies have reported persistent outbreak of algal blooms around the lake shores and increasing mass occurrences of cyanobacteria especially near inshore areas of the lake which is indicative of increased nutrient pollution (Haande et al. [2] and Cózar et al. [17]). Physicochemical measurements along the shores and bays of Lake Victoria were found to differ greatly and are mostly influenced by the extents of the bordering wetlands. This was attributed to Phosphorus (P) and Nitrogen (N) loading in runoff from the catchment and population centres (Cózar et al. [17] and Bracchini et al. [18]). However, earlier research by Tamatamah et al. [19] compared the existing estimates of $\mathrm{P}$ from municipal and runoff inputs concluding that atmospheric deposition represented 55\% of the total $\mathrm{P}$ input to Lake Victoria. Furthermore, Banadda et al. [4] explained that non point pollution sources from around the Murchison Bay was higher than that from point sources 
into the Bay but did not make quantifiable justifications. This research attempts to quantify these estimates in a conclusive way.

Pollutant concentrations in bays largely depend on the inflows and internal processes; such processes may be difficult to ascertain in the ungauged IMB implying that estimating pollutant loading into the Bay seems virtually impossible. However, our working hypothesis is that the use of measured concentrations within the Bay shores may provide plausible estimates of input loading. Such estimates provide point source discharges for the water quality models which are calibrated based on downstream measurements towards the Outer Murchison Bay (OMB).

\subsection{Water quality model}

Numerical water quality models are set up for both the IMB and OMB using Delwaq module in Delft3D. Delft3D is a flexible integrated modelling suite, which simulates 2D and 3D flow, sediment transport and morphology, waves, water quality, ecology and interactions between these processes in time and space. Delft3D consists of several modules, which are linked to and integrate with one-another e.g. D-Flow, D-Morphology, D-Water Quality, D-Ecology and D-Particle Tracking. In this research, D-Flow and D-Water Quality are used. DFlow simulates non-steady flows in relatively shallow water. It incorporates the effects of tides, winds, air pressure, density differences, waves, turbulence, drying and flooding. The output of that module is used as input for the other modules in Delft3D suite (Delft3D-Flow [20]). D-Water Quality simulates the far and mid-field water and sediment quality due to a variety of transport and water quality processes. It includes several advection diffusion solvers and an extensive library of standardised process formulations and substances. It also provides an open system to define additional substances, processes acting on new and existing substances, additional coefficients to be used in the formulae, and external forcing (D-Water Quality [21]).

\subsubsection{General dissolved oxygen model}

Consumption of dissolved oxygen is mainly due to decay of organic matter which may reach the system through discharge of sewage effluent, or indirectly in eutrophic conditions through decay of algal and phytoplankton matter. DWater Quality [21] describes a General DO model based on the basic StreeterPhelps formulation which was derived for a continuous BOD load to a river (Chapra [22]). This model simulates decay of organic matter (BOD), nitrification of Ammonium $\left(\mathrm{NH}_{4}^{+}\right)$and replenishment of DO through reaeration.

Mineralisation of Carbonaceous BOD is subject to a linear and temperature and oxygen dependent decay process as defined in eqn (1) below:

$$
\text { Mineralisation flux }=-R c_{B O D} \times C B O D_{5} \times \vartheta_{B O D}^{(T-20)} \times \frac{\left(O_{2}\right)-D O_{B O D}^{C r}}{D O_{B O D}^{O P t}-D O_{B O D}^{C r}}
$$

where $C B O D_{5}$ is concentration of carbonaceous $\mathrm{BOD}_{5}\left[\mathrm{gO}_{2} / \mathrm{m}^{3}\right] ; R c_{B O D}$ first order rate constant at $20^{\circ} \mathrm{C}\left[\mathrm{d}^{-1}\right] ; \vartheta_{B O D}$ temperature coefficient [-]; T water temperature $\left[{ }^{\circ} \mathrm{C}\right] ;\left(\mathrm{O}_{2}\right)$ DO concentration $\left[\mathrm{gO}_{2} \cdot \mathrm{m}^{-3}\right] ; \quad D O_{B O D}^{C r}$ critical DO 
concentration for BOD mineralization $\left[\mathrm{gO}_{2} / \mathrm{m}^{-3}\right]$ and $D O_{B O D}^{O p t}$ optimal DO concentration for BOD mineralization $\left[\mathrm{gO}_{2} / \mathrm{m}^{-3}\right]$. Nitrification follows a similar reaction at stoichiometry of $\left(\mathrm{NH}_{4}^{+}: \mathrm{O}_{2}: \mathrm{NO}_{3}{ }^{-}=-1:-4.571: 1\left[\mathrm{gN} \cdot \mathrm{m}^{-3}: \mathrm{gO}_{2} \cdot \mathrm{m}^{-3}\right.\right.$ : $\left.\left.\mathrm{gN} . \mathrm{m}^{-3}\right]\right)$. Nitrification proceeds under aerobic conditions only and stops when the water temperature drops below a certain critical level; usually set to $3^{\circ} \mathrm{C}$.

Reaeration depends on the wind speed, stream velocity and water depth. It is formulated as a first order process working on the oxygen deficit as per eqn (2):

$$
\text { Reaeration flux }=R c_{\text {rear }} \times\left(D O_{\text {sat }}-\left(O_{2}\right)\right) \times \vartheta_{\text {rear }}^{(T-20)}
$$

where $R c_{\text {rear }}$ is first order reaeration rate constant $\left[\mathrm{d}^{-1}\right] ; D O_{\text {sat }}$ saturation concentration of DO depending on temperature and salinity $\left[\mathrm{gO}_{2} \cdot \mathrm{m}^{-3}\right] ; \vartheta_{\text {rear }}$ temperature coefficient for reaeration [-]. The 'Sediment oxygen demand' process which allows us to specify additional oxygen consumption by the sediments can be included. This process proceeds without limitation if the oxygen concentration is over $2 \mathrm{mg} / \mathrm{l}$ and stops completely when the concentration drops to $0 \mathrm{mg} / \mathrm{l}$.

Water quality models were created for both the IMB and OMB based on a numerical grid of $250 \times 250 \mathrm{~m}$. The boundaries between the wetlands and IMB were considered as closed, meaning discharges from/into the swamps were neglected and only dynamics caused by main lake water variations were considered. The open boundaries were set at the exit of the IMB into the OMB, and towards the M23 offshore area of the OMB. Monitoring points at M18 and M14 were used to check quality at the IMB exit while M9 and M15 were used to analyse IMB in-shore behaviour. The main discharge locations were at M1, M2, M3 and M4 located at the extreme shores of the IMB while, M10 and M17 were considered as minor discharge points. The hydrodynamic and water quality models are simulated for the period 2001-2011 based on a constant onshore wind speed of $2.5 \mathrm{~m} / \mathrm{s}$. It is assumed that the Lake Victoria epilimnion is deeper than the Murchison Bay implying vertical mixing in the bay hence no need to account for stratification and turnover in the models.

Continuity can be used to assess influence of specific inputs like lake water levels into the system. By assigning a concentration of $1 \mathrm{~g} / \mathrm{m}^{3}$ to all water sources, initial and boundary conditions for the Continuity parameter, the concentration should remain $1 \mathrm{~g} / \mathrm{m}^{3}$ during the simulation, as no processes dilute or concentrate it. If the concentrations significantly deviate from $1 \mathrm{~g} / \mathrm{m}^{3}$ during the simulation, either a source of water has been ignored or the simulation is numerically unstable (D-Water Quality [21]). Continuity values greater than $1 \mathrm{~g} / \mathrm{m}^{3}$, imply overestimation by the water quality model which may be caused by underestimation of volume terms and vice versa. It is on this basis that the models are used to study the effect of the lake level variations on the pollutant concentration in the Bay. 


\section{Results and discussion}

\subsection{Water level variations}

The satellite lake levels corrected for Jinja follow similar patterns with Entebbe measurements and calculated levels (Figure 2). The sharp increase in water levels in 1964 is mainly attributed to the high rainfall and tributary inflows in that period (Piper et al. [5]). Since the differences in elevations are accounted for by the lake bathymetry, water level variations at Entebbe were used as input for the IMB and OMB hydrodynamic models. The lake levels generally declined by about $2 \mathrm{~m}$ in the period 2000-2007; followed by a sharp increase in water levels in the year 2007 after which the lake regains its pre-1998 pattern; this decline was partly attributed to the construction of the Kiira dam at Jinja since the Nile River outflow generally followed the lake levels prior to 2000 .
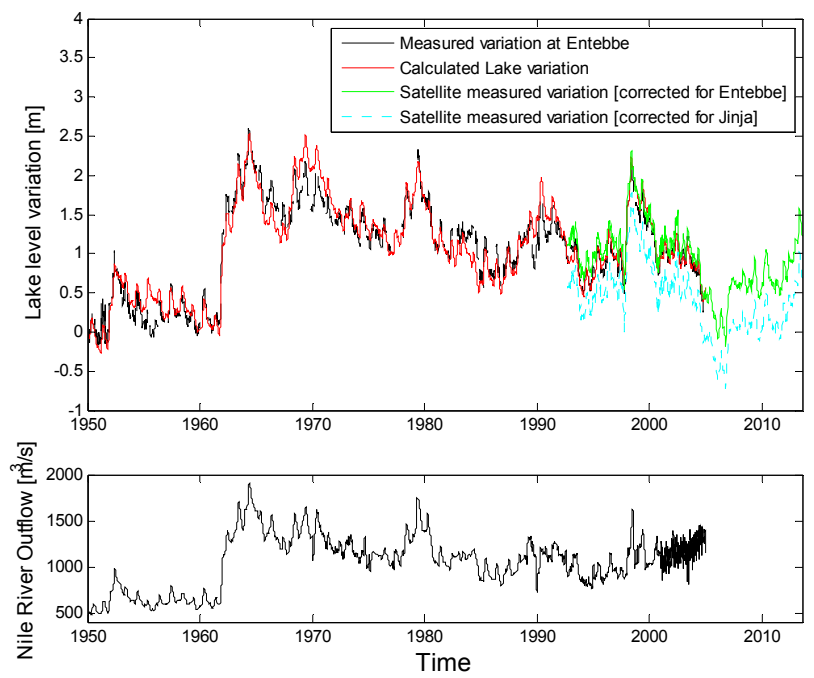

Figure 2: Lake level variations over time as compared to Nile outflow.

\subsection{Murchison Bay hydrodynamics}

Figure 3 shows the average of the non-decayable continuity term in the 20012011 period in the Murchison Bay. It is seen that the IMB flow is not fully controlled by the main lake water variations as compared to the OMB. In fact more than $5 \%$ of the water in the IMB is from the runoff discharges from surrounding wetlands while Lake Victoria contributes about $95 \%$ of the total IMB volume. This is explained by the high continuity errors within the IMB that keep decreasing towards the OMB. The high continuity errors arise because water inflows/outflows from the wetlands were neglected in the hydrodynamic simulations. 


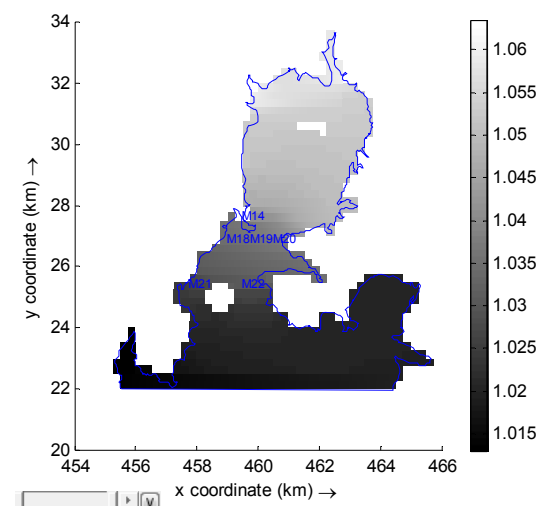

Figure 3: Average of the non-decayable continuity term within the Bay.

The Delwaq models estimated the residence time within the Murchison Bay at 50-100 days and showed that it varied from point to point just as Wallingford and Gibb [23]. However, areas around wetlands at M1, M3 and M4 showed very high residence times often exceeding 10 years. This resonates well with the study by Njuru [24] who estimated the residence time of the Nyanza gulf, Lake Victoria shoreline to be at least 5 years. The mainly circular anticlockwise movement of water in the IMB partly explains the lower pollutant concentrations towards the centre of the bay.

\subsection{Murchison Bay water quality}

Pollution into the IMB generally shows an exponential increase as per Figure 4. In this pollution, effect of point source pollution from industrial wastes, organic and sewage disposal was more significant than diffuse loadings. This is in contradiction to the review by Banadda et al. [4]; although it can logically be argued that all diffuse pollution in essence ends up as point loads into the wetlands and lake through the channels and streams.
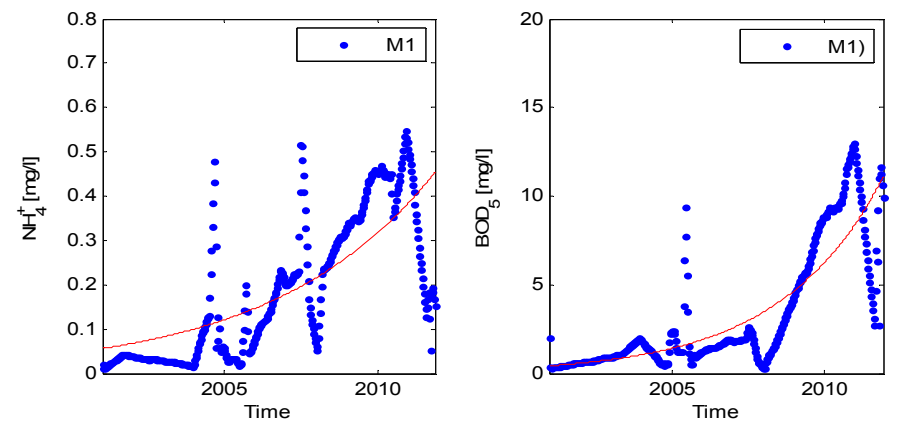

Figure 4: Pollution loading tends into the IMB for M1 for NH4+ and BOD concentrations. 
Water quality models were set up after neglecting the effect of the extensive water hyacinth at the shoreline area and considering only pollutant loadings at M1, M2, M3, M4, M10 and M17. Acceptable results were obtained for NH4+, DO and BOD concentrations using the general DO model for the parameters listed in Table 1.

Table 1: $\quad$ General DO model parameters.

\begin{tabular}{|c|c|r|r|}
\hline Process & Parameter & Value & Unit \\
\hline BOD mineralization & $R c_{B O D}$ & 0.1 & {$\left[\mathrm{~d}^{-1}\right]$} \\
\hline & $\vartheta_{B O D}$ & 1.04 & {$[-]$} \\
\hline & $D O_{B O D}^{C r}$ & 1 & {$\left[\mathrm{gO}_{2} / \mathrm{m}^{-3}\right]$} \\
\hline & $D O_{B O D}^{O p t}$ & 5 & {$\left[\mathrm{gO}_{2} / \mathrm{m}^{-3}\right]$} \\
\hline & $R c_{\text {nit }}$ & 0.1 & {$\left[\mathrm{~d}^{-1}\right]$} \\
\hline & $\vartheta_{\text {nit }}$ & 1.07 & $\vartheta_{B O D}[-]$ \\
\hline & $D O_{\text {nit }}^{C r}$ & 2 & {$\left[\mathrm{gO}_{2} / \mathrm{m}^{-3}\right]$} \\
\hline & $D O_{\text {nit }}^{\text {Opt }}$ & 5 & {$\left[\mathrm{gO}_{2} / \mathrm{m}^{-3}\right]$} \\
\hline & $S W_{\text {rear }}$ & 13 & {$[-]$} \\
\hline
\end{tabular}

Figure 5 shows comparison between simulated and observed water quality parameters within the Murchison Bay. It is seen in the figure that the accuracy of the water quality simulation results improved towards the OMB where greater lake mixing occurs showing the significance of changes by transport of flowing water. This is especially true for monitoring points M14, M18 as compared to M9 and M15 in the IMB. However, it should be noted that the simulation results closer to the shoreline areas (M14) are generally lower for BOD and $\mathrm{NH} 4^{+}$ probably due to diffuse loadings from agriculture that encourage the algal blooms and water hyacinth growth along the shores. This concurs with Bracchini et al. [18] findings in which wetland released chromophoric dissolved organic matter greatly influenced the attenuation of UV and light in the lake water.

The water quality concentrations generally followed the pollution loading pattern rather than lake levels. Even the $2 \mathrm{~m}$ water level decline in the period 2000-2007 did not necessarily yield a significant change in the water quality simulations. By 2011, the $\mathrm{NH}^{+}$levels at the IMB exit had accumulated to $0.15 \mathrm{mg} / 1$ from $0.015 \mathrm{mg} / 1$ in 2001 . The average DO concentration in the IMB was $7 \mathrm{mg} / \mathrm{l}$ while the maximum BOD concentrations ranged from $6.5 \mathrm{mg} / \mathrm{l}$ at the shores to $3 \mathrm{mg} / \mathrm{l}$ at the exit of the IMB. By comparing the average $\mathrm{NH}^{+}$and BOD levels between the IMB shores and exit into the OMB; it can be estimated that lake inflow accounted for about $40-60 \%$ of pollutant dilution in the IMB.

\section{Conclusions}

Lake Victoria level decline in 2000-2006 did not directly affect water quality. Instead, nutrient and BOD accumulation over the simulation period is directly linked to increased pollutant loading. It is moreover noted in the results that the lake level variations affect the water quality by altering flow of water in the IMB 

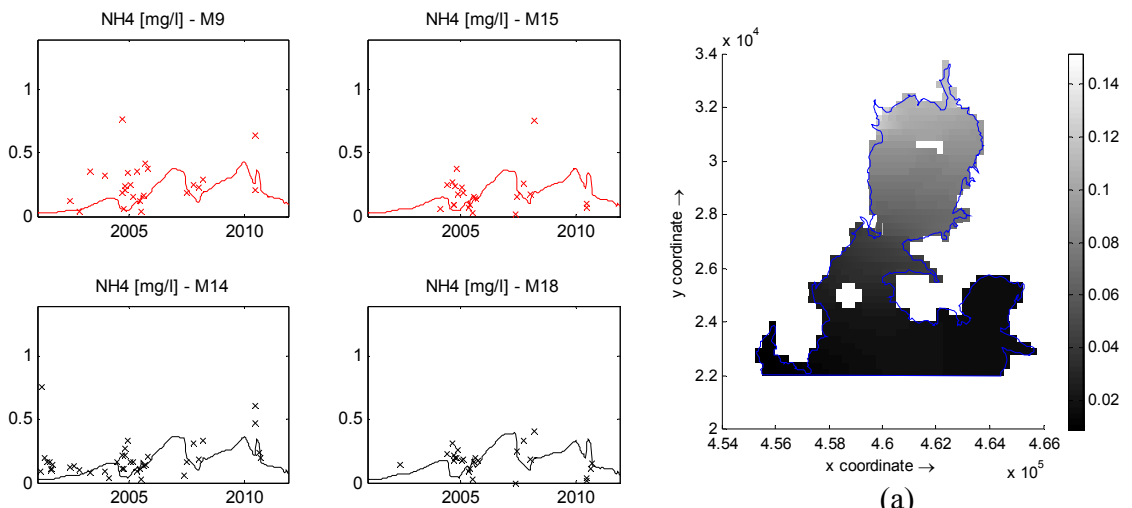

(a)
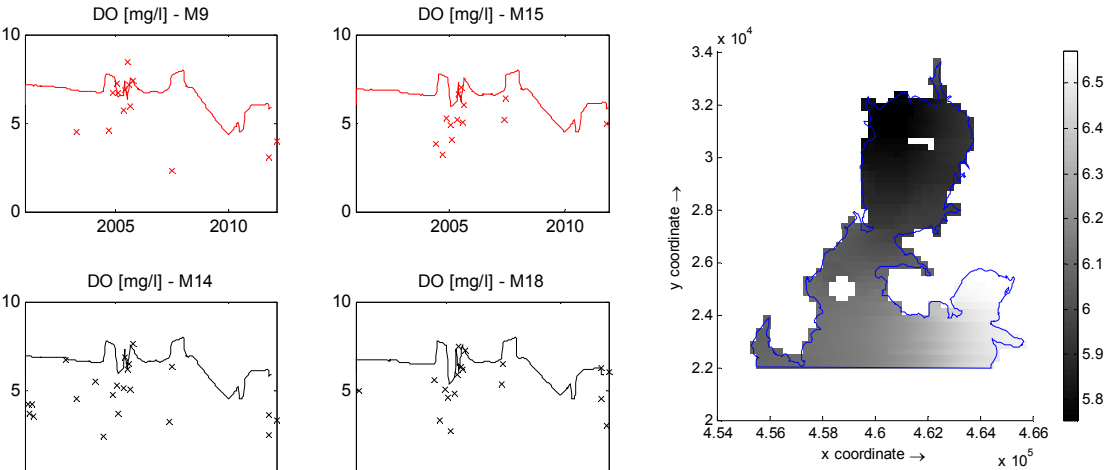

(b)
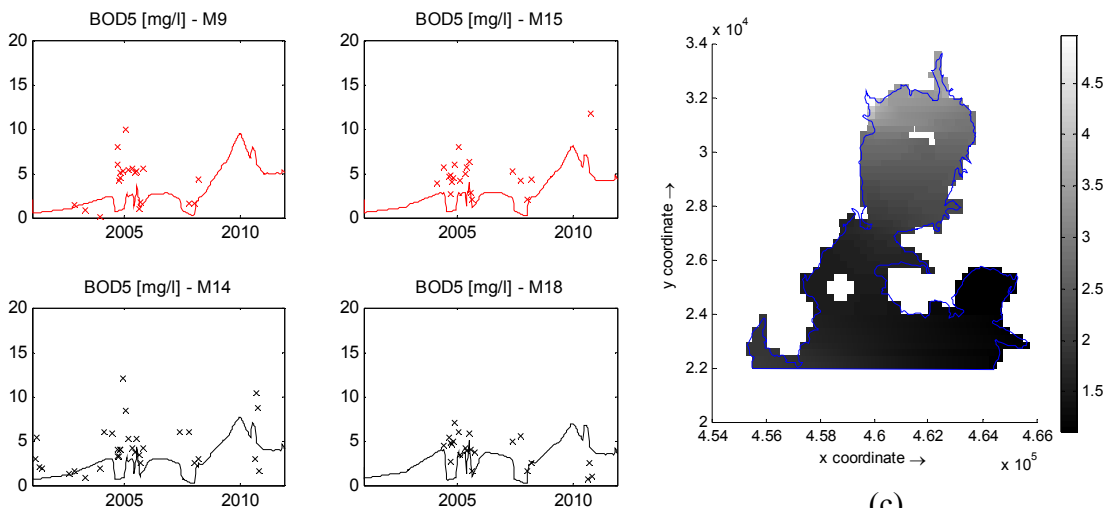

(c)

Figure 5: Simulated $\mathrm{NH}_{4}^{+}$, DO and BOD concentrations in the IMB compared to sparse monthly observations from NWSC, and spatial distribution of $\mathrm{NH}_{4}^{+}$(a), DO (b) and BOD (c) within the Murchison Bay at end of the simulation period (2011). 
and lake contribution in pollutant dilution could be about $60 \%$. The high residence time at the Northern shores partially explains the foul stench and the decreasing clear water levels at the M1, M3 and M4 hotspots since most pollutants are allowed to settle without disturbance caused by water flow.

This research provides a basic DO-BOD- $\mathrm{NH}_{4}{ }^{+}$model that could be used in forecasting and hind casting water quality in the IMB based on the sparse temporal measurements at the IMB. Further improvements of this study may include incorporating sediment oxygen demand and vegetation modules in the model to improve water quality simulations, and improving water level measurements in the IMB. This model can be applied as a decision tool, or applied to study climate and wetland management practices. Determining the chemical compositions of settled solids within the IMB and carbon dating to obtain age of the pollutants might help in forging ways to reclaim the IMB.

\section{Acknowledgements}

The authors would like to thank the VLIR-IUC inter-university development cooperation of Belgium for funding this research under the VLIR-ICP PhD programme. We also would like to thank the National Water and Sewerage Corporation, and the Ministry of Water and Environment, Uganda, for availing the data for this research.

\section{References}

[1] Kaggwa, R.C., Mulalelo, C.I., Denny, P. \& Okurut, T.O. The impact of Alum discharges on a rural tropical wetland in Uganda. Water Res., 35, 795-807. 2001.

[2] Haande, S., Rohrlack, T., Semyalo, R.P., Brettum, P., Edvardsen, B., Lyche-Solheim, A., et al. Phytoplankton dynamics and cyanobacterial dominance in Murchison Bay of Lake Victoria (Uganda) in relation to environmental conditions. Limnol. - Ecol. Manag. Inl. Waters, 41, 20-29. 2011.

[3] Kayima, J., Kyakula, M., Komakech, W. \& S.P, E. A study of the degree of Pollution in Nakivubo Channel, Kampala, Uganda. Appl. Sci. Environ. Manag., 12, 93-98. 2008.

[4] Banadda, E.N., Kansiime, F., Kigobe, M., Kizza, M. \& Nhapi, I. Landusebased nonpoint source pollution: a threat to water quality in Murchison Bay, Uganda. Water Policy, 11, 93-104. 2009.

[5] Piper, B.S., Plinston, D.T. \& Sutcliffe, J. V. The water balance of Lake Victoria. Hydrol. Sci. J., 31, 25-37. 1986.

[6] Yin, X. \& Nicholson, S.E. The water balance of Lake Victoria. Hydrol. Sci. J., 43, 789-811. 1998.

[7] Tate, E., Sutcliffe, J., Conway, D. \& Farquharson, F. Water balance of Lake Victoria : update to 2000 and climate change modelling to 2100 / Bilan hydrologique du Lac Victoria: mise à jour jusqu'en 2000 et 
modélisation des impacts du changement climatique jusqu'en 2100. Hydrol. Sci. J., 49, 574. 2004.

[8] Awange, J.L., Ogalo, L., Bae, K.-H., Were, P., Omondi, P., Omute, P., et al. Falling Lake Victoria water levels: Is climate a contributing factor? Clim. Change, 89, 281-297. 2008.

[9] Kite, G.W. Recent changes in level of Lake Victoria / Récents changements enregistrés dans le niveau du Lac. Hydrol. Sci. J., 26, 233243. 1981a.

[10] Kite, G.W. Analysis of Lake Victoria levels. Hydrol. Sci. J., 27, 99-110. 1982 b.

[11] Swenson, S. \& Wahr, J. Monitoring the water balance of Lake Victoria, East Africa, from space. J. Hydrol., 370, 163-176. 2009.

[12] Kizza, M., Westerberg, I., Rodhe, A. \& Ntale, H.K. Estimating areal rainfall over Lake Victoria and its basin using ground-based and satellite data. J. Hydrol., 464-465, 401-411. 2012.

[13] Kansiime, F. \& Nalubega, M. Wastewater Treatment by a Natural Wetland: the Nakivubo Swamp, Uganda - Ph.D Thesis 1999.

[14] Sekabira, K., Oryem, O.H., Basamba, T.A., Mutumba, G. \& Kakudidi, E. Assessment of heavy metal pollution in the urban stream sediments and its tributaries. Int. J. Environ. Sci. Tech, 7, 435-446. 2010.

[15] Fichtner \& M\&E Associates. Kampala Sanitation Program / UGANDA Feasibility Report 2008.

[16] USDA. http://www.pecad.fas.usda.gov/lakes/images/lake0314.TPJO.1.txt.

[17] Cózar, A., Bergamino, N., Mazzuoli, S., Azza, N., Bracchini, L., Dattilo, A., et al. Relationships between wetland ecotones and inshore water quality in the Ugandan coast of Lake Victoria. Wetl. Ecol. Manag., 15, 499-507. 2007.

[18] Bracchini, L., Loiselle, S.A., Tognazzi, A., Dattilo, A.M., Focardi, S., Cózar, A., et al. The optical qualities of shallow wetland lined bays in Lake Victoria. Wetl. Ecol. Manag., 15, 509-519. 2007.

[19] Tamatamah, R. A., Hecky, R.E. \& Duthie, H. The atmospheric deposition of phosphorus in Lake Victoria (East Africa). Biogeochemistry, 73, 325344. 2005.

[20] Delft3D-Flow. Simulation of multi-dimensional hydrodynamic flows and transport phenomena, including sediments - User Manual 2013.

[21] D-Water Quality. Versatile water quality modelling in 1D, 2D or 3D systems including physical, (bio)chemical and biological processes - User Manual 2013.

[22] Chapra, S.C. Surface Water-Quality Modeling. Waveland Press, Inc. Long Grove, Illinois, Tufts University. 1997.

[23] HR Wallingford \& Gibb. Lake Water Hydrodynamic studies in the Murchison bay area of Lake Victoria - Report Ex 3635. Howbery Park, Wallingford - OXON. 1997.

[24] Njuru, P.G. Physical and biogeochemical gradients and exchange processes in Nyanza Gulf and main Lake Victoria (East Africa) - Ph.D Thesis 2008. 